Ciencia y tecnología

Science and Technology 



\title{
Productos libres de gluten: un reto para la industria de los alimentos
}

\author{
Rafael Villanueva Flores* \\ Universidad de Lima. Perú
}

Recibido: 11 de enero del 2017 / Aprobado: 1 de febrero del 2017

\begin{abstract}
Resumen: Existe un mercado interesante para la industria de los alimentos en los consumidores intolerantes al gluten. Sin embargo, no es sencillo obtener productos libres de gluten con características similares a los que tienen gluten y con el mismo costo. Es importante que en las etiquetas de los alimentos se mencionen los alérgenos utilizados en la elaboración del producto o si se emplean líneas de producción en las que se procesan ingredientes alérgenos, de manera que el consumidor se encuentre mejor informado y evite productos que puedan hacerle daño.
\end{abstract}

Palabras clave: alérgenos / trigo / gluten / industria de los alimentos

\section{Gluten free products: a challenge for the food industry}

ABstRACT: There is an interesting market for the food industry in gluten free consumers. However, it is not easy to get gluten-free products with similar characteristics and cost to those with gluten. It is important that food labels mention the allergens used during production or if production lines, in which allergen ingredients are processed, are used, so that consumers will be well informed an avoid products that may be harmful.

Keywords: allergens / wheat / gluten / food industry

* Correo electrónico: RVillan@correo.ulima.edu.pe 


\section{INTRODUCCIÓN}

La Administración de Alimentos y Medicamentos (FDA, por sus siglas en inglés) señala que existen más de 160 alimentos que pueden provocar reacciones alérgicas en personas sensibles. Ocho de ellos (leche, huevos, pescado, mariscos [crustáceos], nueces de árbol, maní, trigo, y soya $\left.{ }^{1}\right)$ ocasionan el $90 \%$ de las alergias alimentarias y constituyen la fuente de la que se derivan muchos otros productos (FDA, 2010).

Con el fin de ayudar a los estadounidenses a evitar los riesgos que representan los alérgenos alimentarios para su salud, el Congreso de ese país aprobó la Ley sobre el Etiquetado de Alérgenos Alimentarios y Protección al Consumidor (FALCPA, Food Allergen Labeling and Consumer Protection Act) de 2004, que exige a los fabricantes declarar en sus etiquetas los productos elaborados con algún ingrediente considerado dentro de los ocho alérgenos principales. Como resultado, las etiquetas de los alimentos ayudan a los consumidores alérgicos a identificar alimentos o ingredientes peligrosos para que los puedan evitar más fácilmente (FDA, 2010). En el Perú, la Ley 28405, Ley de Rotulado de Productos Industriales Manufacturados, promulgada en el 2004, indica declarar los alérgenos en el rótulo del alimento.

Para el fabricante de alimentos, no solo es importante identificar los alérgenos que emplea en sus procesos productivos, sino también evaluar la presencia de ellos en productos que no los usan en su composición, pero que comparten líneas o plantas con aquellos que sí los utilizan. Es necesario que los consumidores sean informados, mediante el rótulo de las envolturas de los alimentos, si estos contienen alérgenos o han sido procesados en una línea de producción que también se usa para los productos con alérgenos.

Actualmente, los métodos más comunes para detectar alérgenos son el ensayo por inmunoabsorción ligado a enzimas (Elisa) y la reacción en cadena de la polimerasa (PCR). El método Elisa ha sido utilizado por décadas; por otro lado, PCR es una metodología más reciente que cobró importancia cuando se tuvieron que poner en práctica directivas de rotulado para productos genéticamente modificados (Popping, 2009).

1 En la Unión Europea a la mostaza adicionan apio, dióxido de azufre, sésamo, moluscos, lupino (Popping, 2009). 


\section{GLUTEN}

El gluten, que significa 'pegamento' en latín, es el nombre comúnmente utilizado para referirse a una combinación de proteínas encontradas en el trigo, la cebada y el centeno (Dar, 2013). El gluten del trigo contiene de $75 \%$ a $85 \%$ de proteínas, y entre $5 \%$ y $10 \%$ de lípidos, almidón residual, carbohidratos y proteínas insolubles en agua atrapadas en la masa (Nierle y El Baya, 1990). Está compuesto por dos clases principales de proteínas: gliadina (una prolamina) y glutenina (una glutelina) (Hoseney, 1994). Las prolaminas son las proteínas de almacenamiento encontradas en el trigo, cebada y centeno: gliadina, hordeína y secalina, respectivamente (Shewry y Halford, 2002).

Cuando se adiciona agua a la harina de trigo y se le aplica trabajo mecánico (mezclado), las proteínas forman una red continua de gluten y constituyen una masa viscoelástica. Dicha masa es capaz de retener gas y producir productos horneados aireados y livianos, como panes, bizcochos y galletas.

El pan es un producto básico de la canasta familiar para un gran porcentaje de la población mundial. Su uso se remonta a los antiguos egipcios (Samuel, 1996). El gluten de trigo, por su capacidad de retener gas, proporciona al pan propiedades funcionales únicas de aireado y de bajo peso.

\section{ALERGIA AL TRIGO E INTOLERANCIA AL GLUTEN}

Muchas personas sufren de alergia al trigo e intolerancia al gluten. En algunos casos, estas situaciones son tan agudas que exposiciones a pequeñas cantidades pueden ser fatales (Dar, 2013). Las proteínas de almacenamiento del trigo (prolamina y glutelina) son las responsables de la intolerancia al gluten y su efecto tóxico no es reducido por la desnaturalización de la proteína durante el horneado o la hidrólisis enzimática a los péptidos (Urban, 2007).

La enfermedad celiaca es una enteropatía inmune mediada que se desarrolla en pacientes con predisposición genética (Murray, 1999; Schuppan, 2000; Sapone et al., 2012). Incluye casos en los que se presentan síntomas intestinales clásicos, diarrea crónica, pérdida de peso y afines; o síntomas extraintestinales no clásicos, como anemia, osteoporosis, trastornos neurológicos y dermatitis herpetiforme (Murray, 1999; Cosnes et al., 2008; Freitag et al., 2009; Sapone et al., 2012). Su sustrato 
morfológico se define por la presencia de un proceso inflamatorio crónico que afecta a la mucosa y submucosa del intestino delgado, y se caracteriza desde el punto de vista clínico por el surgimiento de diversas manifestaciones sistémicas (Rodríguez, 2010).

La enfermedad celiaca es una dolencia inflamatoria permanente del sistema gastrointestinal que afecta al intestino delgado en individuos genéticamente susceptibles. Las personas celiacas que ingieren gluten sufren daños en sus células intestinales y no pueden asimilar correctamente los nutrientes, lo que les ocasiona deficiencias nutricionales y otros problemas potenciales de salud (Gluten Intolerance Group, 2016). $\mathrm{El}$ factor ambiental es principalmente la ingestión de gluten, mientras que varios genes contribuyen a la predisposición genética (Van Belzen et al., 2003). Los principales factores genéticos son genes HLA-DQ, es decir, genes que codifican DQ2 o DQ8 en el complejo HLA en 6p21. Aproximadamente, el $95 \%$ de los celiacos tienen un DQ2 compuesto por DQB1 * 02 y DA1 * 05, y el $5 \%$ restante tiene un heterodímero ${ }^{2}$ DQ8 (DQB1 * 302 y DQA1 * 03). (Mazzarella et al., 2003; Karell et al., 2003).

Además de la enfermedad celiaca, existen otras reacciones importantes de hipersensibilidad relacionadas con los cereales, tales como alergia al trigo y sensibilidad al gluten (Sapone et al., 2012). La alergia al trigo se define como una reacción adversa inmunológica a las proteínas del trigo, en la que los anticuerpos de inmunoglobulina $\mathrm{E}$ juegan un papel central en la patogénesis de estas enfermedades (Battais et al., 2005). Hoy en día también se reporta sensibilidad no celiaca al gluten (Mattioni, Scheuer, Antunes, Paulino, De Francisco, 2016).

Según la Asociación de Celiacos del Perú, la prevalencia es de 1 en 100 y de 1 en 266 personas en el mundo con esta enfermedad hereditaria y autoinmunitaria. Por cada celiaco diagnosticado, se calcula que hay 10 sin diagnóstico. La mejor manera de controlar la enfermedad celiaca es seguir una dieta libre de gluten y detectar la intolerancia de manera temprana para prevenir daños intestinales.

Una dieta libre de gluten consiste en una combinación de alimentos naturalmente libres de gluten (por ejemplo, frutas, verduras, arroz y carne sin procesar) y alternativas libres de gluten en alimentos sobre la

2 Molécula formada por dos componentes diferentes, pero estrechamente relacionados, como una proteína compuesta por la unión de dos cadenas separadas (http://www.cun.es). 
base de trigo, como el pan y las pastas (Singh y Whelan, 2011). Estas dietas libres de gluten son recomendadas para personas que sufren de dermatitis herpetiforme o enfermedad de Duhring (Deutsch, 2009).

El 24 de julio del 2003, siendo prefecto el cardenal Joseph Ratzinger (luego Benedicto XVI), la Congregación de la Doctrina de la Fe de la Iglesia Católica emitió una carta circular dirigida a los presidentes de las Conferencias Episcopales en la que se indicó que las hostias sin nada de gluten, quibus glutinum ablatum est, eran materia inválida para la eucaristía. Sin embargo, eran materia válida las hostias con la mínima cantidad de gluten necesaria para obtener la panificación sin añadir sustancias extrañas ni recurrir a procedimientos que desnaturalicen el pan. El sacerdote que no comulgue bajo la especie del pan, incluido el pan con una mínima cantidad de gluten, no podría celebrar individualmente la eucaristía ni presidir la concelebración. Se precisó, igualmente que, dada la centralidad de la celebración eucarística en la vida sacerdotal, se debía tener mucha cautela antes de admitir al presbiterado candidatos que no pudieran consumir gluten o alcohol etílico sin grave perjuicio de su salud.

\section{DENOMINACIÓN LIBRE DE GLUTEN}

Uno de los estándares comúnmente utilizados es el 118-1979 del Codex Alimentarius (2008), que indica que un producto debe contener menos de 20 ppm de gluten para ser declarado libre de gluten. El mismo estándar establece que un producto que contiene de 20 a 100 ppm de gluten debe ser declarado bajo en gluten. Una certificación adicional utilizada en los Estados Unidos es la de la Organización de Certificación Libre de Gluten (Gluten Free Certification Association, 2016), la cual manifiesta que para que un producto sea declarado libre de gluten debe contener menos de 10 ppm de gluten. Otro estándar utilizado en los Estados Unidos es el de la Asociación de la Enfermedad Celiaca (Celiac Support Association, 2016), que indica que el producto debe contener menos de 5 ppm para denominarse libre de gluten.

La Federación de Celiacos de España (FACE) precisa que los alimentos en donde los fabricantes aseguren la ausencia de gluten deben ser productos certificados por la marca de garantía (controlado por FACE) con menos de 10 ppm de gluten y también por el ELS (Sistema de Licencia Europeo) con menos de 20 ppm de gluten. 
El Código de Alimentos de Argentina señala, en su artículo 1383, que los productos libres de gluten (denominados sin TACC) no deben superar un máximo de 10 ppm de gluten. En Chile, el Decreto 134/14, que entró en vigencia en julio del 2015 y que modificó el Decreto 977 (Reglamento Sanitario de Alimentos), refiere que los productos libres de gluten son aquellos cuyo contenido no sobrepasa las 3 ppm de gluten; además, que se rotulará la frase libre de gluten en las proximidades del nombre del producto con caracteres de buen realce, tamaño y visibilidad.

Varias compañías venden diferentes kits de Elisa para el análisis del gluten residual. Sin embargo, los kits se basan en al menos dos tipos distintos de antisueros, los llamados anticuerpos Skerritt y los anticuerpos R5. La evidencia presentada en varias reuniones científicas sugiere que estos dos tipos generales de Elisa pueden no dar el mismo resultado analítico de una muestra particular. Por tanto, la definición libre de gluten también puede depender del método utilizado para analizar el gluten residual (Taylor, 2009).

\section{PRODUCTOS LIBRES DE GLUTEN}

La elaboración de productos libres de gluten puede conllevar riesgos de contaminación cruzada por la utilización de líneas o equipos comunes, o ingredientes o aditivos en los cuales no se ha identificado o declarado la presencia del gluten. Por ejemplo, muchas enzimas utilizadas en panificación contienen como vehículo (excipiente) la harina de trigo. Por ello, los sistemas de inocuidad alimentaria contemplan procedimientos para minimizar el riesgo de contaminación cruzada entre productos alérgenos y no alérgenos, a través de una adecuada identificación y gestión de las actividades de recepción, almacenamiento y control de la producción. Estos procedimientos incluyen, entre otros, cuestionarios de alérgenos que se envían a los proveedores para identificar posibles productos alérgenos no declarados.

Debido a la funcionalidad única del gluten en la elaboración de productos horneados, producir alimentos libres de gluten no es una tarea fácil y representa un reto tecnológico. No existe reemplazante único para el gluten de trigo. Este se compone de dos fracciones principales de proteínas: gliadinas, que contribuyen a las propiedades viscosas y extensibilidad de la masa de trigo (Pomeranz, 1988; Don Lichtendonk, Pfijter y Hamer, 2003); y gluteninas, que tienen un papel prominente en las propiedades elásticas y el fortalecimiento de la masa (MacRitchie, 1987; 
Xu, Bietz y Carriere, 2007). El gluten juega un rol crítico en el desarrollo de la estructura de las células y en el volumen del pan, atributos reconocidos por los consumidores. Eliminar el gluten de la harina base trae como consecuencia serios inconvenientes en el procesamiento, estructura, textura y volumen del pan (Dar, 2013).

Las masas y los batidos sin gluten poseen viscosidad y elasticidad diferentes de los que sí tienen, lo que dificulta su procesamiento y maquinabilidad en equipos concebidos para procesar masas con gluten. La composición nutricional de los productos libres de gluten también puede variar en comparación con los productos que tienen gluten. Otro punto que se debe tomar en cuenta es que muchas veces se utilizan cantidades elevadas de grasas y azúcares para enmascarar sabores no agradables en los productos libres de gluten. Así, alimentos horneados libres de gluten se encuentran disponibles en el mercado, pero encontrar uno de calidad sigue siendo una de las cuestiones más importantes para personas intolerantes que desean adherirse completamente a una dieta libre de gluten (Case, 2005).

Existen dos maneras de producir alimentos libres de gluten: una es utilizar ingredientes libres de gluten y la otra es remover el gluten de los ingredientes que lo contengan (Berghofer y Schoenlechner, 2009). Si se piensa en la producción de pan, por ejemplo, además de utilizar ingredientes libres de gluten, se requiere que estos sean adecuados al menos para la elaboración de productos parecidos al pan, para lo cual es necesario que dichos componentes tengan un elevado contenido de carbohidratos. Entre estos se encuentran los cereales sin gluten, como el arroz, el maíz y el sorgo; los granos andinos kiwicha y quinua; y raíces y tubérculos como la papa y la yuca. Para compensar la falta de gluten $-\mathrm{y}$ tener la capacidad de formar una red proteica para generar volumen en el producto horneado-, estos ingredientes deben combinarse con agentes ligantes de agua y espesantes, como goma de algarrobo, goma guar, pentosanos, goma xantana, almidones modificados; agentes formadores de estructura y sabor, entre ellos proteínas de leche, soya, pescado; y agentes surfactantes, como los emulsionantes (Berghofer y Schoenlechner, 2009). Por ello, el producto libre de gluten resulta más costoso que el alimento que contiene gluten. Queda mucha investigación por realizar para obtener un pan libre de gluten con características cercanas al que posee gluten. Sin embargo, galletas dulces y algunos tipos de fideos libres de gluten pueden obtenerse con características bastante parecidas a los que contienen gluten. 
Para el caso de las galletas, la masa es generalmente más pegajosa y menos compacta, lo cual hace que sea más difícil extraerlas del molde. Para el caso de las pastas, se recomienda la utilización de un tanque de pregelatinización en conjunto con la prensa para evitar el empleo de harinas precocidas.

En el mercado peruano se pueden encontrar fideos, canelones y galletas hechos principalmente con harina de maíz, harina de arroz, almidón de papa, almidón de yuca, goma xantana, carboximetil celulosa y colorantes naturales como cúrcuma y annatto (achiote). Igualmente, harinas de uso general elaboradas con una combinación de harina de arroz, almidón de papa, harina de sorgo, harina de yuca y goma xantana.

\section{CONCLUSIONES}

La existencia de un mercado de consumidores intolerantes al gluten ha generado en la industria de los alimentos un interés muy especial por el desarrollo y comercialización de productos libres de gluten. Para el caso particular del pan, la funcionalidad del gluten de trigo en la formación de estructura, textura y volumen en el producto horneado origina que todavía no pueda ser reemplazado por otro ingrediente o combinación de ingredientes. Productos como galletas dulces y algunas formas de fideos si pueden lograrse, aunque tienen un mayor costo. Producir alimentos libres de gluten es un reto tecnológico y constituye un campo en el que hay mucho espacio para la investigación, no solamente en los aspectos científicos y tecnológicos, sino también en la parte comercial.

\section{REFERENCIAS}

Asociación de Celíacos del Perú. (2016). ABC de la celiaquia. Recuperado de http://celia cosperu.org/abc-de-la-celiaquia.html

Battais, F., Courcoux, P., Popineau, Y., Kanny, G., Moneret-Vautrin, D. A., y Denery-Papini, S. (2005). Food Allergy to Wheat: differences in Immunoglobulin E-Binding Proteins as a Function of Age or Symptoms. Journal of Cereal Science, 42(1), 109-117.

Berghofer, E., y Schoenlechner, R. (2009). Overview of Gluten-Free (Cereals and other) Raw Materials and their Properties. En E.K. Arendt y F. Dal-Bello (Eds.), The Science of Gluten-Free Foods and Beverages. St. Paul: AACC International. 
Case, S. (2005). The Gluten Free Diet: How to Provide Effective Education and Resources. Gastroentrology, 128(4), 128-134.

Celiac Support Association. (2016). Defining Gluten Free. Recuperado de http://www.csaceliacs.org/defining_the_term_glutenfree.jsp

Clínica Universidad de Navarra. (2016). Diccionario médico. Recuperado de http://www.cun.es/diccionario-medico/terminos/heterodimero

Codex Standard 118-1979, Norma relativa a los alimentos para regímenes especiales destinados a personas intolerantes al gluten. (2008). Recuperado del sitio de internet del Codex Alimentarius, Normas Internacionales de los Alimentos: http:// www.fao.org/fao-who-codexalimentarius/sh-proxy/en/?lnk=1\& url=https $\% 253 \mathrm{~A} \% 252 \mathrm{~F} \% 252 \mathrm{Fw}$ orkspace.fao.org\%252Fsites $\%$ $252 \mathrm{Fcodex} \% 252 \mathrm{FStandards} \% 252 \mathrm{FCODEX} \% 2 \mathrm{BSTAN} \% 2 \mathrm{~B} 118$ 1979\%252FCXS_118s_2015.pdf

Código Alimentario Argentino. (2013). Capítulo XVII: Alimentos de Régimen y Dietéticos. Recuperado del sitio de internet de la Administración Nacional de Medicamentos, Alimentos y Tecnología Médica: http://www.anmat.gov.ar/alimentos/codigoa/ Capitulo_XVII.pdf

Congregación de la Doctrina de la Fe. (24 de julio de 2003). Carta circular a los presidentes de las Conferencias Episcopales acerca del uso del pan con poca cantidad de gluten y del mosto como materia eucarística. Recuperado de http://www.vatican.va/roman_curia/ congregations/cfaith/documents/rc_con_cfaith_doc_20030724_ pane-senza-glutine_sp.html

Corporación de Apoyo al Celiaco. (2016). Normativa chilena para alimentos exentos de gluten. Recuperado de http://www.coacel. cl/normativa-chilena-para-alimentos-exentos-de-gluten

Cosnes, J., Cellier, C., Viola, S., Colombel, J. F., Michaud, L., Sarles, J., ... y Nion-Larmurier, I. (2008). Incidence of Autoimmune Diseases in Celiac Disease: Protective Effect of the Gluten-Free Diet. Clinical Gastroenterology and Hepatology, 6(7), 753-758.

Dar, Y. L. (2013). Advances and Ongoing Challenges in the Development of Gluten-free Baked Goods. Cereal Foods World, 58(6), 298-304.

Decreto 134/14. Modifica Decreto 977, Reglamento Sanitario de los Alimentos. (1996). Ministerio de Salud de Chile. Recuperado del 
sitio de internet de la Biblioteca del Congreso Nacional de Chile: https://www.leychile.cl/Navegar?idNorma=1073472

Deutsch, H. (2009). Gluten Free Diet and Food Legislation. En E. K. Arendt y F. Dal Bello (Eds.), The Science of Gluten-Free Foods and Beverages. St. Paul: AACC International.

Don, C., Lichtendonk, W. J., Pfijter, J. J. y Hamer, R. J. (2003). Glutenin Macropolymer: A Gel Formed by Glutenin Particles. Journal of Cereal Science, 37(1), 1-7.

Federación de Celiacos de España. (2016). Clasificación de los alimentos. Recuperado de http://www.celiacos.org/la-dieta-singluten/clasificacion-de-los-alimentos.html

Freitag, T. L., Rietdijk, S., Junker, Y., Popov, Y., Bhan, A. K., Kelly, C. P., ... y Schuppan, D. (2009). Gliadin-Primed CD4+CD45RBlowCD25- T Cells Drive Gluten Dependent Small Intestinal Damage After Adoptive Transfer into Lymphopenic Mice. Gut, 58(12), 1597-1605.

Gluten Free Certification Association. (2016). Standards. Recuperado de http://www.gfco.org/get-certified/standards.

Gluten Intolerance Group. (2016). La dieta libre de gluten: Mitos y realidades. Recuperado de https://www.gluten.org/recursos-enespanol/la-dieta-libre-de-gluten-mitos-y-realidades/

Hoseney, R. C. (1994). Principles of Cereal Science and Technology (2. ${ }^{a}$ ed.). St. Paul: AACC International.

Karell, K., Louka, A. S., Moodie, S. J., Ascher, H., Clot, F., Greco, L., ... y Partanen, J. (2003). HLA Types in Celiac Disease Patients Not Carrying the DQA1*05-DQB1*02 (DQ2) Heterodimer: Results from the European Genetics Cluster on Celiac Disease. Human Immunology, 64(4), 469-477.

MacRitchie, F. (1987). Evaluation of Contributions from Wheat Protein Fractions to Dough Mixing and Breadmaking. Journal Cereal Science, 6(3), 259-268.

Mattioni, B., Scheuer, P., Antunes, A., Paulino, N. y De-Francisco, P. (2016). Compliance with Gluten-Free Labelling Regulation in the Brazilian Food Industry. Cereal Chemistry, 93(5), 518-522.

Mazzarella, G., Maglio, M., Paparo, F., Nardone, G., Stefanile, R., Greco, L., ... y Troncone, R. (2003). An Immunodominant DQ8 
Restricted Gliadin Peptide Activates Small Intestinal Immune Response in Vitro Cultured Mucosa from HLA-DQ8 Positive but not HLA-DQ8 Negative Coeliac Patients. Gut, 52(1), 57-62.

Murray, J. A. (1999). The Widening Spectrum of Celiac Disease. The American Journal of Clinical Nutrition, 69(3), 354-365.

Nierle, W., y El-Baya, A. W. (1990). Functionality of Modified Wheat Gluten in Baking. En W. Bushuk y R. Trachuk (Eds.), Gluten Proteins. St. Paul: AACC International.

Pomeranz, Y. (1988). Composition and Functionality of Wheat Flour Components. En Wheat Chemistry and Technology (3. ${ }^{a}$ ed., Vol. II). St. Paul: American Association of Cereal Chemists.

Popping, B. (2009). Challenges in Detecting Food Allergens - Analytical Methods in the Legal Context. En E. K. Arendt y F. Dal Bello (Eds.), The Science of Gluten-Free Foods and Beverages. St. Paul: AACC International.

Rodríguez, L. (2010). Enfermedad celiaca. Información Terapéutica del Sistema Nacional de Salud, 34(2), 49-59. Recuperado de http://www.msc.es/biblioPublic/publicaciones/recursos_propios/ infMedic/docs/vol34n2enfCeliaca.pdf

Samuel, D. (1996). Investigation of Ancient Egyptian Baking and Brewing Methods by Correlative Microscopy. Science, (273), 488-490.

Sapone, A., Bai, J. C., Ciacci, C., Dolinsek, J., Green, P. H. R., Hadjivassiliou, M., ... y Fasano, A. (2012). Spectrum of GlutenRelated Disorders: Consensus on New Nomenclature and 364 Classifications. BMC Med, (10), 13-20.

Schuppan, D. (2000). Current Concepts of Celiac Disease Pathogenesis. Gastroenterology, 119(1), 234-242.

Shewry, P. R. y Halford, N. G. (2002). Cereal Seed Storage Proteins: Structures, Properties and Role in Grain Utilization. Journal of Experimental Botany, 53(370), 947-958.

Singh, J., y Whelan, K. (2011). Limited Availability and Higher Cost of Gluten-Free Foods. Journal of Human Nutrition and Dietetics, 24(5), 479-486.

Taylor, S. (2009). Gluten Free Ingredients. En E. K. Arendt y F. Dal Bello (Eds.), The Science of Gluten-Free Foods and Beverages. St. Paul: AACC International. 
Urban, P. (2007). Ridascreen Gliadin Competitive - Gluten, Prolamin und Gliadine. Der Lebensmittelbrief, 5(6), 82-83.

U. S. Food and Drug Administration. (2010). Alergias a los alimentos. Lo que usted debe saber. Recuperado de http://www.fda.gov/ Food/ResourcesForYou/Consumers/ucm220115.htm.

Van-Belzen, M. J., Meijer, J. W. R., Sandkuijl, L. A., Bardoel, A. F. J., Mulder, C. J. J., Pearson, P. L., ... y Wijmenga, C. (2003). A Major Non-HLA Locus in Celiac Disease Maps to Chromosome 19. Gastroenterology, 125(4), 1032-104.

Xu, J., Bietz, J. A., y Carriere, C. J. (2007). Viscoelastic Properties of Wheat Gliadin and Glutenin Suspensions. Food Chem. 101(3), 1025-1030. 